\title{
Os primeiros dias da Faculdade de Medicina e Cirurgia do Pará: o protagonismo de Antônio Magno e Silva
}

\section{The first days of the School of Medicine and Surgery of Pará, Brazil: the protagonism of Antônio Magno e Silva}

Aristoteles Guilliod de Miranda', José Maria de Castro Abreu Junior

' Universidade Federal do Pará, Instituto Histórico e Geográfico do Pará, Belém, Pará, Brasil

\section{RESUMO}

Por meio de documentos inéditos, este artigo reconstitui os dias iniciais de criação da primeira Faculdade de Medicina da Amazônia brasileira. Alguns fatos e personagens, cuja participação no evento é tradicionalmente minimizada ou ocultada na historiografia convencional, são recuperados no texto. Possíveis razões para esse esquecimento são levantadas.

Palavras-chave: História da Medicina; Faculdades de Medicina; Instituições acadêmicas.

\begin{abstract}
Based on unseen documents, this article reconstructs the creation and initial days of the first School of Medicine of the Brazilian Amazon. Some facts and figures, whose participation in the event is traditionally minimized or hidden in conventional historiography, are retrieved in the text. Possible reasons for this oblivion are raised.
\end{abstract}

Keywords: History of Medicine; Medical Schools; Academic Institutions.

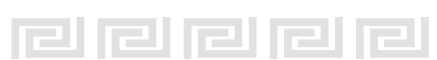

\section{ANTÔNIO MAGNO E SILVA E A FACULDADE DE MEDICINA DO PARÁ}

Ao completar, em 2019, seu primeiro século de existência e sendo considerada o marco primordial do início do ensino médico na Amazônia brasileira, a ideia de criação da Faculdade de Medicina do Pará, posteriormente denominada Faculdade de Medicina e Cirurgia do Pará*, ainda carece de estudos mais aprofundados que façam jus ao real significado da mencionada Instituição para a região.

Alguns textos sobre a criação dessa escola médica chamam a atenção pela abordagem laudatória e um tanto carregada de messianismos e predestinações, como por exemplo a revista Pará-Medico, de setembro de 1922. Por muito tempo, o tópico "Faculdade de Medicina do Pará", presente nesse número especial editado em comemoração ao bicentenário da Independência, publicado três anos após o surgimento da Faculdade, foi uma espécie de cânone reproduzido ad nauseam por quem escreveu sobre esse assunto em geral, sem menção da fonte bibliográfica - e, como tal, sem contestações, "[...] estabelecendo seu próprio passado através da repetição quase que obrigatória $[\ldots]^{\prime \prime 2}$, consequentemente criando e reproduzindo mitos.

No tópico relativo à criação da Faculdade de Medicina, na mencionada publicação, lê-se ${ }^{3}$ :

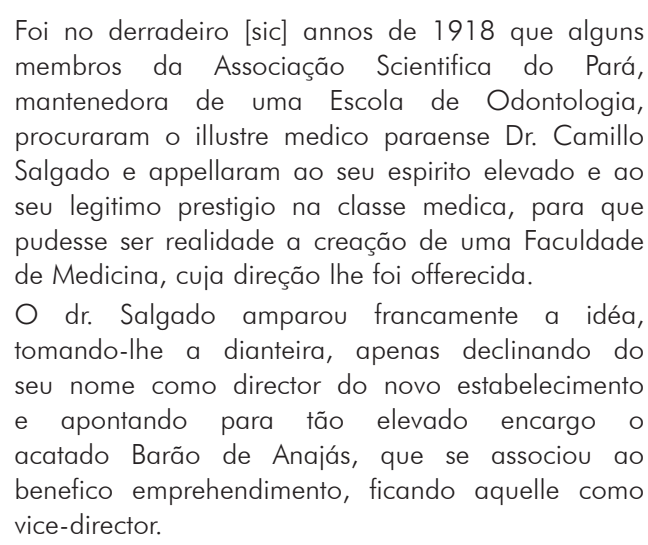

\footnotetext{
* Era assim que a Faculdade era conhecida em seus primórdios; o "de Cirurgia" surgiu em algum momento após 1923. Em alguns relatórios dos governadores, outros nomes são observados com menos frequência, como "Faculdade Livre de Medicina do Pará"1.
}

\section{Correspondência / Correspondence:}

Aristoteles Guilliod de Miranda

Trav. 14 de Abril, 1716. Bairro: Guamá. CEP: 66063-475 - Belém, Pará, Brasil - Tel.: +55 (91) 99986-1289

E-mail:guilliod@gmail.com/guilliod@ufpa.br 
Analisando o texto acima, temos lançada a ideia de criação de uma Faculdade de Medicina por "[...] membros da Associação Scientifica do Pará [...]", que, apresentada ao "[...] illustre medico paraense dr. Camillo Salgado [...]", foi por ele acatada, "[...] tomando-Ihe a dianteira [...]". $\bigcirc$ trecho alimentaria o entendimento de que a fundação da escola médica se deveu particularmente ao médico Camilo Salgado, figura de destaque na Medicina local, gozando de grande prestígio social, com suas atividades médicas frequentemente divulgadas pela imprensa e hoje considerado como um "santo popular", em uma devoção que por vezes ultrapassa a regiãot. De qualquer modo, ainda que não se queira desmerecer o papel de Camilo Salgado, mesmo os memorialistas que se apoiavam particularmente no texto da Pará-Medico contrariam essa tese. Clóvis Meira, um dos autores que mais escreveu sobre a Faculdade, além dos textos em livro, afirma, em entrevista ao jornal $\bigcirc$ Liberal, nas celebrações pelos 70 anos de fundação da escola: "Quem propôs a criação de uma faculdade de Medicina aqui no Pará foi Antônio Magno e Silva, membro de uma associação médico-científica que já mantinha uma escola de Odontologia [...]"15 (Figura 1).

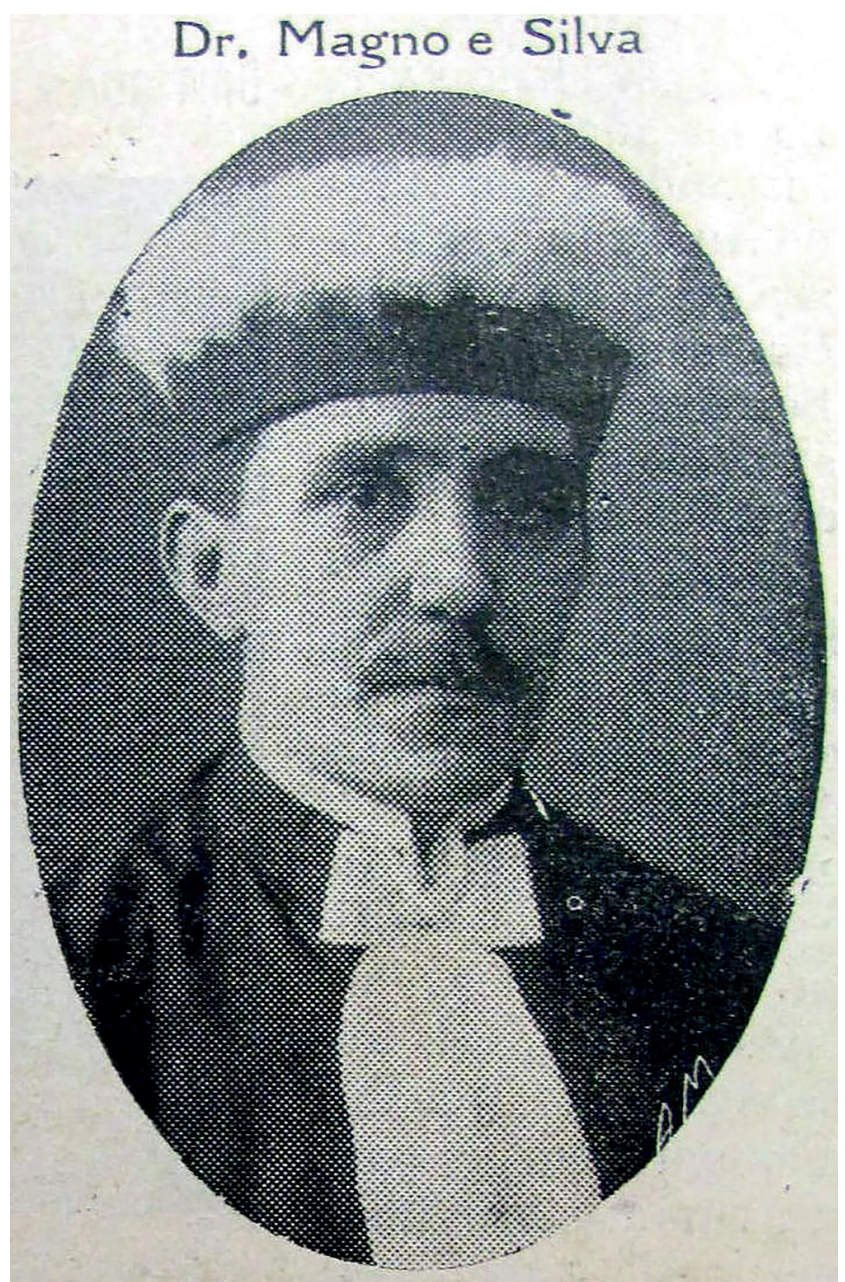

Fonte: Antônio Magno e Silva. A Semana. 1925 abr;7(365).

Figura 1 - Antônio Magno e Silva
Todavia, o protagonismo de Magno e Silva se apaga diante da ideia de um médico na condição de mito-fundador. A "primazia" de Camilo Salgado vai se juntar às histórias de outras Faculdades de Medicina criadas na velha República, as quais têm, em sua construção narrativa, a figura um médico mentor e condutor, o qual acaba se transformando em uma espécie de patrono, como: Arnaldo Vieira de Carvalho, na Faculdade de Medicina da Universidade de São Paulo; os médicos Nilo Cairo e Vitor Ferreira do Amaral, na Universidade do Paraná; Otávio Freitas, na Faculdade de Medicina de Recife; ou Eduardo Sarmento Leite, na Faculdade de Medicina do Rio Grande do Sulb.

Entretanto, o texto da Pará-Medico parece sugerir a ideia de "uma faculdade a procura de um autor", quando afirma que "[...] alguns membros [...]" levaram a ideia até Camilo Salgado e este foi o responsável pelos demais acontecimentos. Considerando que "[...] a história é uma narrativa de eventos: todo o resto resulta disto $[\ldots]^{117}$, cabe ao pesquisador buscar, nos relatos históricos, os diversos vieses, inclusive os silêncios; nesse caso específico, tentar descortinar os sujeitos ocultados pelo médico transformado em mito, fato constantemente reforçado por seus biógrafos.

No que diz respeito à Associação Científica do Pará, uma confusão se estabeleceu entre esta e a Sociedade Propagadora das Ciências, o que também acabaria sendo repetido pelos autores que se apoiaram no texto da Pará-Medico de 1922. Ribeiro ${ }^{8}$ relata que essa Associação fora primeiramente conhecida como Sociedade Propagadora das Ciências, o que não procede, pois se trata de duas entidades diferentes.

A Sociedade Propagadora das Ciências, por vezes também chamada Centro Propagador de Ciências, foi uma associação fundada em 23 de janeiro de 1918. Tal instituição foi responsável pela criação da Escola de Agronomia e Veterinária, sem relação com a Escola de Odontologia, criada em 1914, e muito menos com a de Medicina. A confusão entre os memorialistas deve ter ocorrido quando, em 1918, o Centro Propagador de Ciências criou outra faculdade de Odontologia em Belém, cuja duração foi muito breve, sendo os alunos da mesma, após acordo, absorvidos pela Escola de Odontologia mais antiga'.

Sobre a Escola de Odontologia, o jornal Estado do Pará, de 17 de maio de 1914, informou a fundação de uma Escola Livre de Odontologia, por iniciativa do professor Joaquim Vianna, do farmacêutico Leandro Tocantins, dos odontólogos Magno e Silva e Carmelino Salgado e do médico Jayme Aben-Athar. Ainda segundo a notícia, a nova escola estava de acordo com a Lei Orgânica do Ensino, com o curso seguindo o modelo do Curso de Odontologia da Faculdade de Medicina do Rio de Janeiro? 
Para Ribeiro ${ }^{8}$, a Escola de Odontologia foi fundada em 4 de julho de 1914, na casa do professor Joaquim Tavares Vianna ${ }^{\ddagger}$, sob sua presidência, e contando com membros como Antônio Magno e Silva, Carmelino Salgado, Antônio Periassú, Camilo Salgado, Pinheiro Sozinho, Jayme Aben-Athar e o farmacêutico Lima e Silva, sendo intitulada "Escola Livre de Odontologia do Pará". O grupo transformou-se na Congregação da nova instituição e nomeou Joaquim Tavares Vianna como diretor, Antônio Magno e Silva como vice e Lima e Silva como secretário, respectivamente. Antônio Magno e Silva tornou-se diretor a partir de 1917, cargo que deixou somente em 1939 com sua morte. É durante a gestão de Antônio Magno e Silva, a partir de uma ideia sua e por resolução da Congregação da escola, em deliberação unânime, que foi criada, em 9 de janeiro de 1919, a Faculdade de Medicina do Pará $^{8}$, na mesma reunião em que surgiu a Associação Scientifica do Pará, inicialmente chamada de Associação Medico-dentaria do Pará.

Do mesmo modo que o texto do Pará-Medico de 1922, o relato contido no opúsculo comemorativo aos 90 anos da Faculdade de Odontologia da Universidade Federal do Pará não registra a fonte pesquisada, resultando em outro texto "canônico" a ser repetido, ainda que dele surja uma data inaugural para a Faculdade de Medicina - 9 de janeiro - reproduzida nos impressos iniciais da escola médica, juntamente com $\circ 1^{\circ}$ de maio, que marca a sua instalação oficial, ambas podendo ser consideradas como "[...] vestígios datados da memória [...]", isto é, "[...] aquilo que fica gravado como data precisa de um acontecimento $[\ldots]^{111}$.

Ao compilarmos a ata da reunião da Escola de Odontologia, temos detalhes dessa criação da Faculdade de Medicina, bem como da Associação Scientifica. Por sua importância e até mesmo pelo seu ineditismo, transcrevemos o trecho da sessão extraordinária de 9 de janeiro de 1919, da Congregação da Faculdade de Odontologia, em que se relata a criação da Faculdade de Medicina ${ }^{12}$ :

\begin{abstract}
Em seguida $\circ$ Dr. Director lembra a ideia da fundação de uma Faculdade de Medicina nesta Capital, atendendo a necessidade de haver o concurso d'essa sciencia em todo o Estado que ainda precisa de ser saneado e da assistência d'esses apóstolos da sciencia, porque embora pareça que o numero desses que exercem esse sacerdocio já seja avultado para uma Capital como a nossa, é todavia uma verdade que muitas vezes são insufficientes para attender aos multiplos casos que se dão entre a população. E se considerar-se que 0 interior do Estado ressente-se da falta de medicos, sobretudo de hygienistas que ensinem e appliquem as regras salutares da sciencia e que levem o socorro e as practicas da medicina e da Cirurgia aos que d'ellas tenham necessidade, ainda serão poucos os que em seis annos depois da fundação d'esta Faculdade,
\end{abstract}

isto é, quando precisamente a primeira turma de diplomados entrará a exercer a nobre profissão da humanidade, para conseguir o saneamento das zonas que são assoladas pelas diversas endemias reinantes. E se considerarmos ainda que a cultura nunca é demais, porque ella estabelece o gráo de adiantamento de um povo, essa ideia terá aos applausos geraes e trará, de futuro, beneficios reaes.

Na sequência da reunião, Magno e Silva propôs as bases de uma associação designada "Associação Medico-dentaria do Pará", sociedade civil destinada a "[...] estabelecer, manter e superintender uma Faculdade de Medicina n'este Estado [...]" que ofereceria "[...] os cursos de medicina, odontologia, pharmacia e obstetricia $[\ldots]^{112}$.

Presentes à reunião: Antônio Magno e Silva (dentista), Hermógenes Pinheiro (médico), Álvaro Gonçalves (dentista), Fernandes Penna (médico), Renato Franco (farmacêutico e dentista) e Evaristo Silva (médico), todos pertencentes ao corpo docente da Odontologia, os quais deveriam ser reconhecidos como os reais fundadores da Faculdade de Medicina\$.

O evento repercutiu na imprensa, com o jornal Folha do Norte, dias depois, publicando a seguinte notícia: "Dentro de poucos dias será fundado nesta cidade um importante estabelecimento de ensino superior que se denominará Faculdade de Medicina do Pará [...]". E, prosseguindo, o texto oferece uma surpresa: "Esta feliz idéa, nascida no seio dos mais ilustres membros da nossa classe medica [...]" (grifo nosso), já mudando o foco das ações do grupo inicial, em uma atitude premonitória quanto ao reconhecimento dos pioneiros ${ }^{13}$.

Em contraponto à notícia da Folha do Norte, o Estado do Pará parece restabelecer a verdade ao publicar a seguinte notícia ${ }^{14}$ :

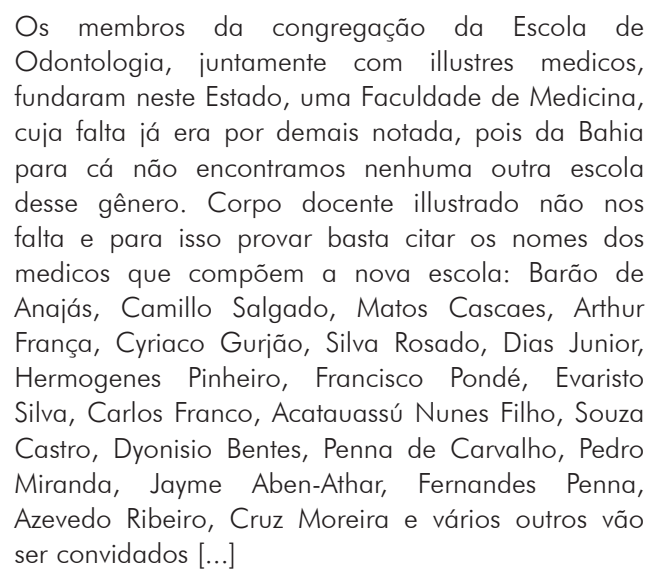

Entretanto, a Folha do Norte publicou, por vários dias, notícias sobre a nova faculdade em fase de criação, incentivando a adesão dos futuros alunos e sem nada mencionar sobre fundação e fundadores. Um detalhe curioso: em várias notas publicadas, o título da notícia reúne a Faculdade de Medicina e a Escola

\footnotetext{
‡ Joaquim Tavares Vianna (1870-1959), farmacêutico, com uma vida dedicada ao magistério, foi fundador, professor e diretor da Faculdade de Odontologia, professor e diretor da Escola de Farmácia, catedrático do colégio estadual Paes de Carvalho, da Escola Normal, além de professor em inúmeros outros colégios da capital paraense ${ }^{10}$.

$\S$ Ainda que o dentista João Amaral tenha assinado a ata, na mesma consta que deixou de comparecer à reunião ${ }^{12}$.
} 
de Odontologia do Pará, ressaltando, assim, a ligação entre as duas entidades ${ }^{15,16,17}$. $\bigcirc$ mesmo se observa na notícia convocatória para os exames de admissão ao curso médico, o que reforça a existência dos laços entre ambas $^{18}$

O que se observa é que, desde o princípio, os fatos ocorridos naquele 9 de janeiro raramente são mencionados nos textos sobre a criação da Faculdade de Medicina e Cirurgia do Pará, tornando a data quase um evento apócrifo. Seria por que o protagonismo da Escola Livre de Odontologia ofuscaria, de certo modo, a efetiva participação dos médicos na criação da Escola? Por tudo isso, torna-se fundamental buscar a narrativa dos fatos em seu nascedouro - a ata da reunião.

A Associação, criada naquela data e inicialmente denominada Associação Medico-dentaria do Pará, teve seu nome modificado para Associação Scientifica do Pará por proposição do professor João Renato Franco, apresentada e aprovada em reunião da Congregação em 7 de fevereiro de 1919. A nova agremiação era constituída por sócios fundadores e efetivos, e pelos professores a serem nomeados futuramente, além dos sócios beneméritos, aqueles que fizessem donativos não inferiores a um conto de reis ou que realizassem serviços reconhecidamente dignos de distinção. Sua finalidade era "[...] estabelecer, manter e superintender uma Faculdade de Medicina [...], que compreenda, com o maior desenvolvimento e conhecimentos scientificos os cursos de medicina, odontologia, pharmacia e obstetricia [... $]^{112}$.

Um fenômeno histórico só pode ser explicado plenamente se for estudado em seu momento ${ }^{19}$. Uma faculdade de Medicina, portanto, não surgiria isolada de um contexto maior, principalmente nas décadas iniciais do século $X X$, o que é percebido nas justificativas de Magno e Silva para a implantação do ensino médico, apoiando seus argumentos nas pautas vigentes do período, como o saneamento dos sertões. Lima $^{20}$ refere que, no fim da década de 1910, o movimento de saneamento dos sertões, ou saneamento rural, alcançou grande visibilidade. $\bigcirc$ país havia (re) descoberto um interior abandonado e com uma população analfabeta e doente. Resolver essa questão era entendido como o pilar para a construção de uma nacionalidade. Hochman ${ }^{21}$ denomina esse período de "A era do Saneamento" e, entre 1916 e 1920, elenca quatro marcos cronológicos como fundamentais para sintonizar as ideias de saneamento como uma pauta importante para políticos e intelectuais incluírem na agenda nacional. São eles: 1) a enorme repercussão do discurso do médico Miguel Pereira", pronunciado em 1916, caracterizando o Brasil como um "[...] imenso hospital [...]"; 2) a divulgação, nesse mesmo ano, do relatório da expedição médico-científica do Instituto Oswaldo Cruz ao interior do Brasil, que revelou uma população doente, improdutiva, atrasada, abandonada e sem nenhuma identificação com a pátria; 3) os artigos na imprensa do médico Belisário Penna ${ }^{* *}$, reunidos no livro $\bigcirc$ Saneamento do Brasil, publicado em 1918; e 4) as ações da Liga Pró-Saneamento, entre os anos de 1918 e 1920, período inicial da reestruturação dos serviços de saúde federais.

Mesmo com todo esse contexto histórico e as motivações alegadas por Magno e Silva, por mais favorável que o momento fosse, de nada adiantaria se não houvesse um amparo legal que favorecesse a iniciativa. A grande alavanca para essa expansão do ensino médico na velha República se deu em 5 de abril de 1911, com a Lei Orgânica do Ensino, instituída pelo Decreto $n^{\circ}$ 8.659, que ficou conhecida como Lei Rivadávia Corrêa, em função do seu idealizador ${ }^{\dagger \dagger}$. Tal Lei apresentava um caráter extremamente liberal e positivista, garantindo autonomia sobre as escolas particulares, extinguindo a ação fiscalizadora do Governo Federal ${ }^{24}$.

Se, por um lado, a Lei possibilitou a abertura de várias instituições de ensino superior, muitas não tinham qualidade. Para Fernando Magalhães ${ }^{\ddagger}$, a Lei Rivadávia Corrêa foi "[...] um bacanal [...]", determinando a proliferação de "[...] universidades de bairro, faculdades de lugarejo, escolas de povoado [...]" que dispensavam as exigências oficiais, além do recurso de ensino por correspondência que dispensava o espaço, garantindo lucro ${ }^{25}$. Cita-se o caso da Universidade Escolar Internacional26, que oferecia diversos cursos superiores por correspondência, entre os quais o de Medicina. Ficou famoso o caso do jornal carioca A Noite que, por 60.000 reis, fez o seu porteiro diplomar-se em médico na referida Universidade 27 .

Para tentar reverter esses problemas, em 18 de março de 1915, o então ministro da Justiça e Negócios Interiores, Carlos Maximiliano, referendou o Decreto $\mathrm{n}^{\circ}$ 11.530, e o presidente Wenceslau Brás sancionou a nova Lei de Ensino, que substituiu a reforma anterior,

\footnotetext{
"Miguel da Silva Pereira (1871-1918), formado na Faculdade de Medicina do Rio de Janeiro em 1906, tornando-se catedrático de Clínica Médica em 1910. Foi membro da Academia Nacional de Medicina, lembrado como homem de poucos trabalhos publicados, mas um primoroso orador e conferencista. Proferiu sua famosa frase em um discurso para saudar Aloysio de Castro, tendo a peça oratória grande repercussão por afirmar que, à exceção de capitais como Rio de Janeiro ou São Paulo, que eram mais ou menos saneadas, e de algumas outras cidades, "[...] o Brasil ainda é um imenso hospital [...]"22. Não obstante esse trecho consagrado seja citado à exaustão, o discurso original é pouco conhecido atualmente. Para ter uma leitura integral do mesmo, ver Sán ${ }^{23}$.

** Belisário Augusto de Oliveira Penna (1868-1939), sanitarista brasileiro, nascido em Barbacena e formado em Medicina na Bahia, em 1890, trabalhou com Oswaldo Cruz fazendo campanhas sanitárias em diversos estados e convencendo governantes de que era imperioso fazer o saneamento e a profilaxia rural no Brasil. Escreveu também diversas obras sobre o assunto que tiveram grande repercussão, como O Saneamento do Brasil ${ }^{22}$.

t† Rivadávia da Cunha Corrêa (1866-1920), gaúcho, de Santana do Livramento, bacharel em Direito pela Faculdade de São Paulo (1887), foi deputado, senador e prefeito do Distrito Federal. Também foi ministro da Justiça e Interior, de 1910 a 1913, tendo assumido interinamente o Ministério da Fazenda em 1913 , sendo efetivado nesse cargo após ser exonerado do outro Ministério ${ }^{24}$.

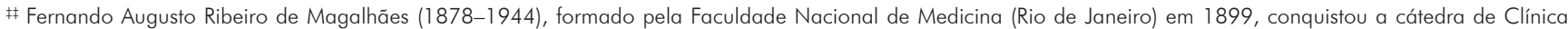
Obstétrica da referida faculdade em 1922, assumindo a direção da mesma em 1930 e a reitoria da Universidade Federal do Rio de Janeiro em 1931 . Apontado
} como um dos maiores profissionais do seu tempo, publicou diversos trabalhos sobre temas de sua especialidade ${ }^{22}$. 
restringindo em muito seus direitos e facilidades. Os estabelecimentos de ensino voltavam a ser fiscalizados pelos setores competentes do governo e o currículo precisava ser equiparado às instituições federais congêneres, no caso do ensino médico, as Faculdades do Rio de Janeiro e da Bahia ${ }^{24}$. Foram essas transformações na legislação do ensino o dispositivo legal que permitiu a abertura de uma Faculdade de Medicina no Pará.

Deve-se entender também que a ideia de Magno e Silva poderia ter ficado perdida no livro de atas, mesmo com as facilidades legais. Outra razão para a Faculdade sair do papel foi o apoio da classe médica, pelo menos de uma parcela dessa. Oliveira ${ }^{27}$, em relatório sobre o serviço de fiscalização do exercício da Medicina, registrou, no período, a presença de 98 médicos no Pará, sendo 62 formados na Faculdade de Medicina do Rio de Janeiro, 30 na Faculdade de Medicina da Bahia e seis em escolas estrangeiras. Os dados, ainda que tenham caráter oficial, são incompletos, uma vez que o autor afirma que a maioria dos médicos militares se recusou a registrar o diploma.

Além da quantidade suficiente de profissionais para um empreendimento desse porte, Rodrigues ${ }^{28}$ demonstra que, nos anos de 1910, os médicos paraenses finalmente conseguiram se organizar em uma corporação coesa. As disputas partidárias, que se deram nos primeiros anos republicanos, entre outros fatores que prejudicavam a união do grupo, foram colocadas de lado, permitindo a criação da Sociedade Médico-Cirúrgica do Pará em 1914. Tal agremiação buscava uma identidade de classe que emancipasse os profissionais da Medicina de todas as falhas que pudessem atrapalhar que a referida categoria assumisse a posição destacada que julgava merecer ${ }^{28}$. Importante destacar que a pauta de criar uma escola médica na região não era assunto desconhecido daquela associação, uma vez que, poucos dias após a instalação da Sociedade Médico-Cirúrgica, em 15 agosto de 1914, a imprensa referia, entre os projetos da nova sociedade, a criação de uma faculdade de Medicina no Pará. A nota ${ }^{29}$, não assinada, destacava as vantagens da instituição e sentenciava:

A idéa da creação de uma Faculdade de Medicina no Pará, alimentada e encaminhada pela Sociedade Médico-Cirurgica será fatalmente posta em execução mais anno menos anno, para alegria da terra paraense.

Nos anos posteriores, entre 1914 e 1919, a Sociedade Médico-Cirúrgica do Pará, ao menos por meio de sua revista, silenciou sobre o tema. Porém, em 1919, alguns de seus componentes abraçariam a causa de Magno e Silva. Dentre esses médicos, os que figuraram na ata de 3 de abril de 1919, quando o primeiro corpo docente da Faculdade de Medicina tomou posse, foram os seguintes: Mário Midosi Chermont (Física Médica), Camilo Salgado dos Santos (Clínica Médica), Francisco Caribé da Rocha (História Natural), Hermógenes Pinheiro (Anatomia Descritiva), Manoel Augusto Fernandes Penna (Histologia), Dionísio Ausier Bentes (Fisiologia), Antônio Acatauassú Nunes Filho (Microbiologia), Raymundo de Mattos Cascaes (Terapêutica Clínica Experimental e Arte de Formular), Barão de Anajás Antonino Emiliano de Souza Castro (Patologia Geral), Jayme Aben-Athar (Anatomia e Fisiologia Patológicas), Raymundo da Cruz Moreira (Anatomia Médico-Cirúrgica), Carlos Arnóbio Franco (Higiene), Francisco de Souza Pondé (Medicina Legal), Acylino de Leão Rodrigues (Clínica Médica, primeira cadeira), Arthur Pinto de França (Clínica Médica, segunda cadeira), Antonino Emiliano de Souza Castro (filho) (Clínica Médica, terceira cadeira), Oswaldo Barbosa (Clínica Médica, quarta cadeira), Camilo Salgado (Clínica Cirúrgica, primeira cadeira), João Batista Penna de Carvalho (Clínica Cirúrgica, segunda cadeira), Lauro Antunes de Magalhães (Clínica Cirúrgica, terceira cadeira), Antônio Joaquim da Silva Rosado (Clínica Ginecológica), Pedro Miranda (Clínica Oftalmológica), Chaves de Freitas (Clínica Otorrinolaringológica), Cyriaco Gurião (Clínica Pediátrica e Higiene Infantil), Otto Santos (Clínica Pediátrica Cirúrgica e Ortopedia), Isidoro Azevedo Ribeiro (Clínica Dermatológica e Sifiligráfica), Evaristo Silva (Clínica Neurológica), Antônio Porto de Oliveira (Clínica Psiquiátrica), Agostinho de Menezes Monteiro (Clínica Obstétrica) e Jayme da Silva Rosado (Radiologia Clínica) ${ }^{30}$. Ainda que o quadro de professores viesse a sofrer alterações nos meses seguintes, eram esses os docentes ${ }^{\S \S}$ que a Faculdade de Medicina contava para começar a funcionar, a partir de sua instalação programada para $1^{\circ}$ de maio daquele ano, portanto, em menos de um mês.

Já a partir desse momento, Magno e Silva desapareceu dos documentos oficiais como membro fundador da escola médica. Possivelmente, os elementos que animavam aquela parcela de médicos no empreendimento seriam o Barão de Anajás, seu primeiro diretor, e Camilo Salgado, vice, ambos citados na notícia da instalação da Faculdade, em $1^{\circ}$ de maio de 1919, como estando à frente de "[...] alguns clínicos paraenses [...]" responsáveis pela iniciativa de criação da escola ${ }^{32}$, por mais que o Folha do Norte, noticiando o mesmo fato, mencione a ligação com a Odontologia $^{33}$ :

A Associação Scientifica do Pará, que há dois annos mantem a Escola Livre de Odontologia, prestes a equiparar-se, conseguiu vêr realizada a idéa de fundação de uma Faculdade de Medicina, que teve franca acolhida de todos os que se interessam pelo engrandecimento da nossa terra, notadamente a classe medica, que a amparou sympaticamente [...]

\footnotetext{
$\S \S$ Embora figure na ata, Jayme Aben-Athar não assinou a mesma e, por consequência, não tomou posse naquela data, perdendo sua condição de fundador. Em seu lugar, mais tarde, foi nomeado, para lecionar Anatomia e Fisiologia Patológicas, João Prisco dos Santos. Nos anos subsequentes, essas alterações são numerosas,
} mostrando o período de instabilidade pelo qual a Faculdade passou até o ano de 1922, quando a congregação ganhou mais consistência ${ }^{31}$ 
Em ambos os casos, o noticiário omite qualquer participação de Magno e Silva no acontecimento. Aliás, vale o registro de que ele estava na cerimônia oficial de instalação da Faculdade no dia $1^{\circ}$ de maio: como aluno! Ironicamente, o primeiro nome citado na relação ${ }^{32}$. Esqueceram que ele era o diretor da Faculdade de Odontologia? Que tinha pensado a escola de Medicina? E que, apostando nela, iria fazer seu curso ali? Diante de tantas evidências, tentaremos adiante tirá-lo do esquecimento ou pelo menos buscar alguns fatos que possam ter contribuído para tal comportamento.

\section{UM ESQUECIMENTO PROPOSITAL?}

Criada a Faculdade de Medicina e Cirurgia do Pará, em 1919, logo o grupo inicial de seus idealizadores deixa de ser citado nas narrativas oficiais, ficando reduzido ao vago termo "[...] alguns membros da Associação Scientifica do Pará [...]"13. Entre eles, Antônio Magno e Silva, aquele que consta na ata criadora como o autor da ideia. Era de se esperar que a história fizesse justiça ao seu ato, mas não foi assim que aconteceu: a história oficial, entre lembrar e esquecer, optou pelo segundo.

Antônio Magno e Silva era odontólogo, formado em 1905, no Rio de Janeiro ${ }^{34}$. Após retornar a Belém, foi um dos fundadores da Escola Livre de Odontologia, onde seguiu carreira acadêmica e administrativa, tendo sido professor catedrático de Clínica, vice-diretor e diretor partir de 1917, somente deixando a direção por sua morte, em 1939. Exerceu o mandato de deputado estadual a partir do governo Enéas Martins, até à revolução de $1930^{35}$. Em 1924, figurou como um dos quatro primeiros doutores formandos pela Faculdade de Medicina e Cirurgia do Pará, ao lado de Bianor Penalber, Hipollito Carelli e Honorato Filgueiras? (Figura 2).
Por ocasião de sua formatura, deixou registrado, na sua tese ${ }^{36}$, a seguinte mensagem aos filhos:

\begin{abstract}
Quando, aos 34 annos de edade e ha 6 annos atraz, ingressei na Faculdade de onde saio hoje, para cultivar meu espirito no conhecimento das sciencias medicas, não o fiz pela satisfação de ser doutor, numa época da existência em que as illusões não mais seduzem, mas para dar a vocês este exemplo de perseverança, que traduz uma dedicação suprema, uma orientação segura, na escarpada da vida $[\ldots]$
\end{abstract}

Referindo-se à nova escola e seus componentes, agradeceu também a "[...] dedicação estoica com em que se entregaram ao ensino [...]" os professores Camilo Salgado (Cirurgia), Acylino de Leão, Oswaldo Barbosa, Arthur França (Clínica), Agostinho Monteiro (Obstetrícia) e Prisco dos Santos, esse último em Microbiologia, Anatomia Patológica e Higiene ${ }^{36}$. Sobre o fato de ter participado da criação da Faculdade, nem uma citação. João Renato Franco, companheiro de jornada nos primórdios das duas escolas, assim justifica: "Magno e Silva [era] o mestre erudito, a cultura especializada, a modéstia personalizada $[\ldots]^{1137}$. E em verbete biográfico ${ }^{38}$, publicado em 1970, reforça a importância da participação de Magno e Silva na criação das duas escolas:

[João Renato Franco] Integrou a banca examinadora que funcionou pela primeira vez na Escola de Odontologia do Pará, da qual foi um dos fundadores. [...] Juntamente com Antônio Magno e Silva, na época diretor da Escola de Odontologia, fundou e organizou, no seu primeiro ano de existência, a Faculdade de Medicina do Pará, contando ainda com a colaboração de todos os professores da Escola de Odontologia e, os quais, no segundo ano de funcionamento da mesma, emanciparam-na e entregaram-na ao dr. Camilo Salgado.

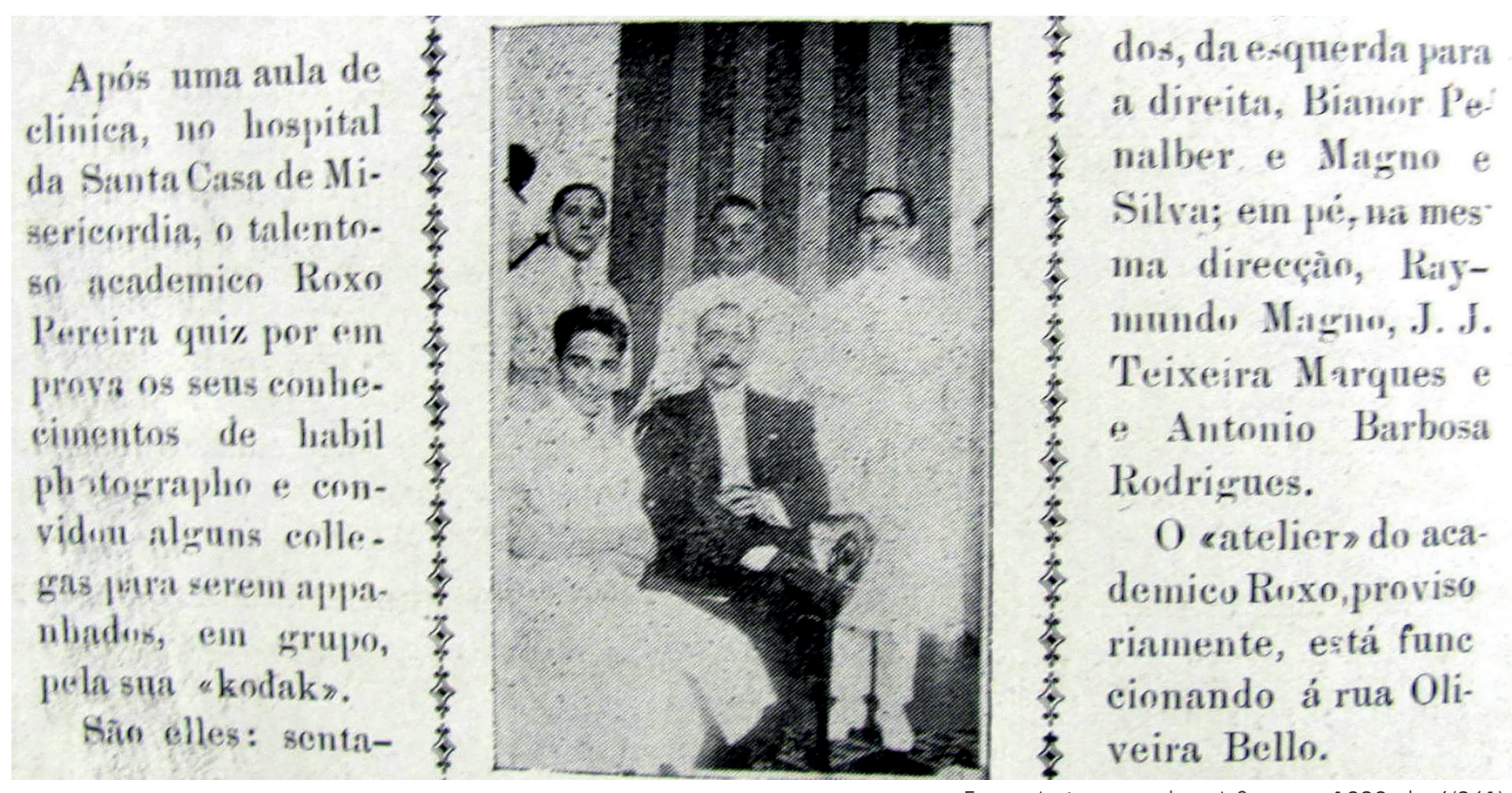

Figura 2 - Notícia, com foto, de Magno e Silva (no centro, de escuro) com outros colegas acadêmicos de Medicina 
Depois da formatura em Medicina, Magno e Silva continuou a exercer conjuntamente a Odontologia, atuando também como médico, além de seguir sua carreira política como deputado.

Curiosamente, a sempre aqui lembrada revista Pará-Medico, de setembro de 1922, publicada apenas três anos após a criação da Faculdade de Medicina, omite o nome de Magno e Silva na gênese da escola médica, mencionando apenas os "[...] alguns membros [...]" da entidade mantenedora da Escola de Odontologia. Disso resulta uma questão importante: o que se desejava manter como memória? A que se deveu esse esquecimento decorrido tão pouco tempo dos fatos originais? $\bigcirc$ que dificultou a construção de sua memória histórica, considerando a relevância do feito de Magno e Silva, ainda que rememorado por ocasião do falecimento desse, "mantendo a tradição de tentar recuperar os ditos esquecidos da história"39? Conforme a Folha do Norte ${ }^{35}$ :

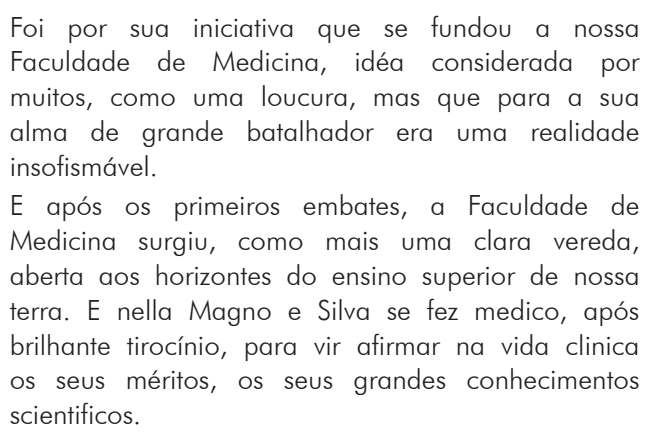
Faculdade de Medicina, idéa considerada por muitos, como uma loucura, mas que para a sua alma de grande batalhador era uma realidade insofismável.

E após os primeiros embates, a Faculdade de Medicina surgiu, como mais uma clara vereda, aberta aos horizontes do ensino superior de nossa terra. E nella Magno e Silva se fez medico, após brilhante tirocínio, para vir afirmar na vida clinica os seus méritos, os seus grandes conhecimentos scientificos.

Entre os presentes ao enterro ou que se manifestaram à beira do túmulo, apenas representantes da Faculdade de Odontologia. Não há menção de ninguém ligado à Faculdade de Medicina. Nas condolências enviadas à família, por meio de cartas, cartões e telegramas, várias pessoas são citadas, entre elas um único professor da Faculdade de Medicina, - Dr. Porto de Oliveira. Estabelecimentos comerciais e instituições de ensino, como o Ginasio Paraense, mereceram citação. Da Faculdade de Medicina, nada é mencionado ${ }^{35}$. Na nota de agradecimento da família, publicada dias depois, também nada relacionado à Faculdade de Medicina ${ }^{40}$. $\bigcirc$ estranhamento se torna ainda maior, quando se percebe que, depois de formado, Magno e Silva permaneceu ligado à Faculdade, estando lotado como auxiliar de ensino de Clínica Médica ${ }^{41}$. Mesmo assim, não escapou de ser rapidamente afastado das histórias de sua criação. Por mais que isso seja mencionado no noticiário de sua morte, esse fato logo desaparece dos relatos oficiais, ofuscado pela figura mítica de Camilo Salgado, falecido no ano anterior, 1938, e alvo de várias homenagens incrementadas a partir da sua morte. Quando seu papel circunstancialmente é lembrado, a tradição oral preservou uma anedota a respeito da fundação da Faculdade de Medicina do Pará, segundo a qual, quando jovem, Magno e Silva teria viajado para o Rio de Janeiro para formar-se em Medicina. Entretanto, por motivos desconhecidos, regressou como dentista, para aborrecimento de seu pai. Esse, desejando ver seu filho formado em Medicina a todo custo, mas já sem recursos para custeá-lo em outro estado, obrigou-o a criar uma

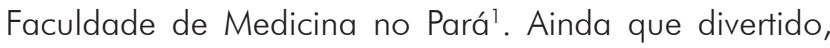
o chiste reduz demais seu protagonismo em um evento tão importante. Talvez, no fundo, fosse esse mesmo - objetivo, colocar os integrantes da Sociedade Médico-Cirúrgica do Pará como os únicos personagens dessa história. Divindades podem ter os seus ciúmes, mas cabe aos historiadores levantar esses véus de esquecimento, de buscar e expor os fatos históricos, lutar contra o apagamento dos rastros ${ }^{42}$.

Embora seu papel na criação do Curso de Medicina tenha desaparecido, a memória de Magno e Silva foi justamente preservada na Odontologia: nas comemorações pelo $70^{\circ}$ aniversário de criação do Curso no Pará, alusiva ainda ao centenário da instituição do ensino odontológico no Brasil, o Conselho Universitário da Universidade Federal do Pará instituiu a Medalha Professor Antônio Magno e Silva, num justo reconhecimento a um dos criadores do Curso $^{43}$; enquanto que a Faculdade de Medicina, sempre que recorda suas origens, reserva-lhe apenas o silêncio.

\section{REFERÊNCIAS}

1 Miranda AG, Abreu Jr. JMC. Memória histórica da Faculdade de Medicina Cirurgia do Pará 19191950: da fundação à federalização. Belém: Edição dos Autores; 2009. 511 p.

2 Hosbawm E. A invenção das tradições. In: Hobsbawm E, Ranger T, organizadores. A invenção das tradições. 4. ed. São Paulo: Paz e Terra; 2006. $316 \mathrm{p}$.

3 Faculdade de Medicina do Pará. Para-Medico. 1922 set;2(10):362-5.

4 Miranda AG, Abreu Jr JMC. Camilo Salgado: revisitando 0 mito. Rev Estud Amazon. $2015 ; 11(2): 128-56$.
5 Os 70 anos da Faculdade de Medicina. $O$ Liberal. Belém, 1989 out 26, p. 2.

6 Sarinho CT. Faculdades de medicina do Brasil: as dez mais antigas. Natal: Nordeste Gráfica; 1989. $266 \mathrm{p}$.

7 Veyne P. Como se escreve a história. 3. ed. Brasília: UnB; 1995. 202 p.

8 Ribeiro PRC. A Faculdade de Odontologia como unidade predecessora da UFPA. In: Beckmann C, Corrêa RC, organizadores. Odontologia: 90 anos. Belém: Edufpa; 2005. 79 p.

9 Escola Livre de Odontologia. Estado do Para. Belém, 1914 mai 17, p. 2. 
10 Professor Joaquim Viana. Faleceu ontem o venerando mestre paraense. Provincia do Para. Belém, 1959 abr 12, p. 8.

11 Pollak M. Memória e identidade social. Estud Hist. 1992;5(10):200- 12.

12 Escola Livre de Odontologia do Pará. Livro de atas da Congregação. Ata de 9 de janeiro de 1919.

13 Faculdade de Medicina do Pará: a sua fundação. Folha do Norte. Belém, 1919 jan 15, p. 1.

14 Escola de Odontologia e Faculdade de Medicina do Pará. Estado do Para. Belém, 1919 fev 12, p. 2.

15 Faculdade de Medicina e Escola de Odontologia do Pará. Folha do Norte. Belém, 1919 mar 1, p. 1.

16 Faculdade de Medicina e Escola de Odontologia do Pará. Folha do Norte. Belém, 1919 mar 4, p. 1.

17 Faculdade de Medicina e Escola de Odontologia do Pará. Folha do Norte, Belém, 1919 mar 6, p. 1.

18 Faculdade de Medicina e Escola de Odontologia do Pará. Exames de admissão ao curso medico. Folha do Norte. 1919 mar 11, p. 1.

19 Bloch M. Apologia da história ou o ofício do historiador. Rio de Janeiro: Jorge Zahar; 2001. $159 \mathrm{p}$.

20 Lima NT. Um sertão chamado Brasil: intelectuais e representação geográfica da identidade nacional. Rio de Janeiro: Revan, IUPERJ-UCAM; 1999. 232 p.

21 Hochman G. A era do saneamento: as bases da política de saúde pública no Brasil. São Paulo: Hucitec, Anpocs; 1998. 261 p.

22 Lacaz CS. Vultos da medicina brasileira. São Paulo: Helicon; 1963.

23 Sá DM. Miguel Pereira e o Brasil doente. In: Hochman G, Lima NT, organizadores. Médicos intérpretes do Brasil. São Paulo: Hucitec; 2015. $666 \mathrm{p}$.

24 Borges MR. A história da Escola de Medicina e Cirurgia do Rio de Janeiro. Rio de Janeiro: Revinter; 2008. 819 p.

25 Magalhães F. $\bigcirc$ centenário da Faculdade de Medicina do Rio de Janeiro 1832-1932. Rio de Janeiro: Typ. A. P. Barthel; 1932.

26 Celebridades magazine. $\bigcirc$ Malho. 1913;11 (531):3.

27 Oliveira JP. Fiscalização do exercício da medicina e polícia sanitária. In: Araujo HCS. A prophylaxia rural no Estado do Pará. Belém: Livraria Gillet; 1922. Vol. 1, cap. 9, p. 194-214.
28 Rodrigues SF. Esculápios tropicais: a institucionalização da medicina no Pará, 18891919 [dissertação]. Belém (PA): Universidade Federal do Pará, Instituto de Filosofia e Ciências Humanas, Programa de Pós-Graduação em História Social da Amazônia; 2008. 163 p.

29 Sociedade Medico-Cirurgica do Pará. Projectos animadores: assistencia publica - uma Faculdade de Medicina do Pará. Estado do Para. Belém, 1914 ago 18, p. 1.

30 Faculdade de Medicina do Pará. Livro de atas: termos de posse dos professores. 1919.

31 Beckmann C. Uma fonte para a história da Faculdade de Medicina e Cirurgia do Pará. Rev Cult Para. 2002 jul;13(2):255-60.

32 Faculdade de Medicina do Pará: sua installação. Estado do Para. Belém, 1919 mai 3, p. 1.

33 Faculdade de Medicina do Pará: a sua inauguração. Folha do Norte. Belém, 1919 mai 3, p. 1.

34 Brasil. Diário Oficial da União, 2 set 1905, p. 4320.

35 Homenagens posthumas ao dr. Magno e Silva: commovente aphoteose por ocasião de seus funeraes. Folha do Norte. Belém, 1939 jan 28, p. 4.

36 Magno e Silva A. Etio-pathogenia das cirrhoses do fígado. Belém: Papelaria Americana; 1925.

37 Franco R. Bodas de prata da Faculdade de Odontologia. Folha do Norte. 1939 set 14, p. 1.

38 Alencar GL, editor. Quem é quem no Pará. Belém: Persona; 1970.

39 Santos MP. $\bigcirc$ sensível acesso ao passado: a memória e o esquecimento. In: XXV Simpósio Nacional de História; 2009 jul 12-17; Fortaleza, CE. São Paulo (SP): Associação Nacional dos Professores Universitários de História; 2009. CD-ROM.

40 Dr. Magno e Silva.: agradecimento. Estado do Para. Belém, 1939 fev 5, p. 4.

41 Faculdade de Medicina e Cirurgia do Pará. Relatorio do anno de 1935 apresentado a congregação pelo director Dr. Camillo Salgado. Belém: Typ. da Livraria Gillet; 1936.

42 Ricoeur P. A matéria, a memória e o esquecimento. Campinas: Unicamp; 2007.

43 Universidade Federal do Pará. Conselho Universitário. Resolução n 546, de 24 de outubro de 1984. Institui a Medalha Professor Antônio Magno e Silva comemorativa ao $70^{\circ}$ aniversário de criação do Curso de Odontologia.

Recebido em / Received: 25/2/2018 Aceito em / Accepted: 26/6/2018 